\title{
Rotigotine Transdermal Patch for Motor and Non-motor Parkinson's Disease: A Review of 12 Years' Clinical Experience
}

\author{
Vanessa Raeder ${ }^{1,2} \cdot$ Iro Boura $^{1,3} \cdot$ Valentina Leta $^{1,3} \cdot$ Peter Jenner $^{4} \cdot$ Heinz Reichmann ${ }^{2} \cdot$ Claudia Trenkwalder $^{5,6}$. \\ Lisa Klingelhoefer ${ }^{2} \cdot K$. Ray Chaudhuri ${ }^{1,3}$
}

Accepted: 20 December 2020 / Published online: 9 February 2021

(c) The Author(s) 2021

\begin{abstract}
Motor and non-motor symptoms (NMS) have a substantial effect on the health-related quality of life (QoL) of patients with Parkinson's disease (PD). Transdermal therapy has emerged as a time-tested practical treatment option, and the rotigotine patch has been used worldwide as an alternative to conventional oral treatment for PD. The efficacy of rotigotine on motor aspects of PD, as well as its safety and tolerability profile, are well-established, whereas its effects on a wide range of NMS have been described and studied but are not widely appreciated. In this review, we present our overall experience with rotigotine and its tolerability and make recommendations for its use in PD and restless legs syndrome, with a specific focus on NMS, underpinned by level 1-4 evidence. We believe that the effective use of the rotigotine transdermal patch can address motor symptoms and a wide range of NMS, improving health-related QoL for patients with PD. More specifically, the positive effects of rotigotine on non-motor fluctuations are also relevant. We also discuss the additional advantages of the transdermal application of rotigotine when oral therapy cannot be used, for instance in acute medical emergencies or nil-by-mouth or pre/post-surgical scenarios. We highlight evidence to support the use of rotigotine in selected cases (in addition to general use for motor benefit) in the context of personalised medicine.
\end{abstract}

\section{Introduction}

Both motor and non-motor symptoms (NMS) of Parkinson's disease (PD) affect health-related quality of life (QoL), with the latter having a major impact [1-4]. NMS underpin the prodromal stage of PD and are prevalent from the de novo manifestation of motor PD through to the palliative stages [5, 6]. While substantial advances have been

Valentina Leta

valentina.leta@nhs.net

1 Parkinson's Foundation Centre of Excellence, King's College Hospital, London, UK

2 Department of Neurology, Technical University Dresden, Dresden, Germany

3 Department of Neurosciences, Institute of Psychiatry, Psychology and Neuroscience, King's College London, London, UK

4 Neurodegenerative Diseases Research Group, School of Cancer and Pharmaceutical Sciences, Faculty of Life Science and Medicine, King's College London, London, UK

5 Department of Neurosurgery, University Medical Centre Göttingen, Göttingen, Germany

6 Paracelsus-Elena Klinik, Kassel, Germany

\section{Key Points}

While the efficacy of the rotigotine transdermal patch on motor aspects of Parkinson's disease is well-established, the awareness of its impact on a wide range of non-motor symptoms is limited.

The rotigotine transdermal patch may be beneficial for the treatment of sleep impairment due to nocturnal motor symptoms and early-morning off; in addition, emerging results indicate efficacy for the management of fluctuation-related pain, apathy, and depression.

The rotigotine transdermal patch may play a key role in nil-by-mouth scenarios in acute management pathways in some countries, such as emergency situations or the intensive care environment, including during the current coronavirus disease 2019 (COVID-19) healthcare crisis.

made in addressing the management of motor symptoms in PD, the management of NMS remains largely pragmatic with a poor evidence base beset with barriers to treatment [7]. A large European study reported widespread nondeclaration of NMS in clinics, with deleterious effects on 
patients [8]. Further, recent guidelines from the National Institute for Health and Care Excellence and the International Parkinson and Movement Disorder Society (MDS) Evidence-Based Medicine (EBM) committee guidelines on the management of NMS in PD $[9,10]$ recognized the treatment of NMS as a key unmet need. Of note, a substantial body of evidence supports the use of the rotigotine patch for a range of NMS in PD in addition to its well-established efficacy in motor symptoms. The non-oral approach offered by the transdermal route constitutes a potential advantage given the number of limitations to oral therapies that may exist in PD from de novo to advanced stages [11].

The non-ergot dopamine agonist (DA) rotigotine, applied as a silicone-based patch, has shown activation of all dopaminergic $\left(D_{1-5}\right)$ receptors, especially with high functional potency at the $\mathrm{D}_{1}, \mathrm{D}_{2}$, and $\mathrm{D}_{3}$ receptors, along with binding affinity to selected serotonergic $\left(5-\mathrm{HT}_{1 \mathrm{~A}}\right)$ receptors and adrenergic $\left(\alpha_{2}\right)$ receptors (Table 1) $[12,13]$. In terms of structure, it closely resembles dopamine, along with apomorphine, and mimics the action of levodopa (Fig. 1) [14-16]. Applied as a patch once daily, rotigotine offers a potential treatment option of continuous drug delivery (CDD) as plasma levels remain stable for $24 \mathrm{~h}$ [17]. CDD is associated with fewer motor fluctuations and a reduced propensity for dyskinesia than intermittent doses of the same drug [18]. A preclinical study on the administration of rotigotine showed stable extracellular levels in the striatum, resulting in continuous dopaminergic stimulation [19].

In 2008, the initial rotigotine formulation was affected by stability problems. A second polymorphic crystalline form of rotigotine was identified, which presented to the naked eye as a 'snowflake'. To counteract the formation and growth of these damaging crystals, cold chain storage and distribution was introduced [22]. These issues were resolved by

Table 1 Receptor-binding profile and functional potency [12, 13, 20, 21]

\begin{tabular}{lllllll}
\hline Affinity for dopamine receptors $^{\mathrm{a}}$ & & \multicolumn{2}{l}{ Functional potency at dopamine receptors $^{\mathrm{a}}$} & Affinity for non-dopamine receptors $^{\mathrm{b}}$ \\
\hline$D_{1}$ & $\mathrm{pK}_{\mathrm{i}} 7.08$ & ++ & $D_{1}$ & $\mathrm{pEC}_{50} 9.6$ & ++++ & $5-\mathrm{HT}_{1 \mathrm{~A}}>>5-\mathrm{HT}_{1 \mathrm{D}}>>5-\mathrm{HT}_{2 \mathrm{~B}}$ \\
$D_{2}$ & $\mathrm{pK}_{\mathrm{i}} 7.87$ & ++ & $D_{2}$ & $\mathrm{pEC}_{50} 10.4$ & ++++ & $\alpha_{2 \mathrm{~B}}>\alpha_{2 \mathrm{C}}>\alpha_{1 \mathrm{~A}}$ \\
$D_{3}$ & $\mathrm{pK}_{\mathrm{i}} 9.15$ & ++++ & $D_{3}$ & $\mathrm{pEC}_{50} 8.2$ & +++ & \\
$D_{4.2}$ & $\mathrm{pK}_{\mathrm{i}} 8.41$ & +++ & & & + \\
$D_{4.4}$ & $\mathrm{pK}_{\mathrm{i}} 7.82$ & ++ & $D_{4}$ & $\mathrm{pEC}_{50} 7.7$ & + \\
$D_{4.7}$ & $\mathrm{pK}_{\mathrm{i}} 8.22$ & +++ & & & ++ \\
$D_{5}$ & $\mathrm{pK}_{\mathrm{i}} 8.27$ & +++ & $D_{5}$ & $\mathrm{pEC}_{50} 7.7$ & ++ \\
\hline
\end{tabular}

$p E C_{50}$ functional potency at the dopamine receptor, $p K_{i}$ binding affinity at the dopamine receptor

${ }^{\mathrm{a}} \mathrm{D}_{1}, \mathrm{D}_{2}, \mathrm{D}_{3}, \mathrm{D}_{4}, \mathrm{D}_{4.2}, \mathrm{D}_{4.4}, \mathrm{D}_{4.7}$, and $\mathrm{D}_{5}$ are dopamine receptors

${ }^{\mathrm{b}} \alpha_{1 \mathrm{~A}}, \alpha_{2 \mathrm{~B}}$, and $\alpha_{2 \mathrm{C}}$ are adrenergic receptors; $5-\mathrm{HT}_{1 \mathrm{~A}}, 5-\mathrm{HT}_{1 \mathrm{D}}$, and 5- $\mathrm{HT}_{2 \mathrm{~B}}$ are 5-hydroxytryptamine receptors

Fig. 1 The aminotetralin structure of rotigotine is similar to that of dopamine but more rigid. The 5-OH and $N$-propyl substituents increase the dopaminereceptor activity and its specificity, whereas the thiophene on the $N$-ethyl substituent increases the dopamine $\mathrm{D}_{2}$ receptor selectivity and lipid solubility of the molecule $[14,15]$

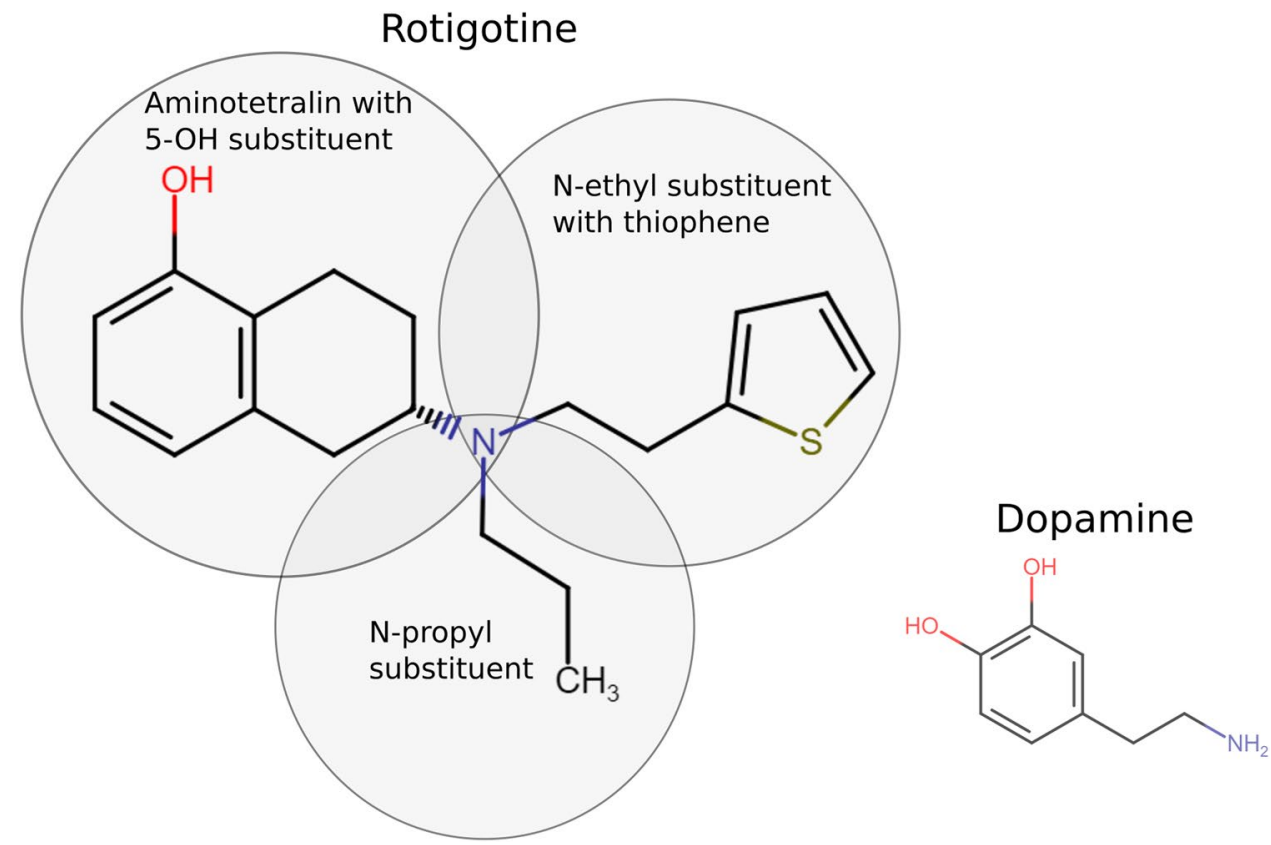


revising the formulation. The new temperature-stable patch, which contains the second polymorphic form, did not crystallize and was approved by the US FDA and the European Medicines Agency in 2012 [23].

\section{Methodology}

We conducted a literature search in PubMed to identify all potentially relevant studies published until March 2020. The reference lists of relevant articles were also screened. The PubMed search was conducted with various combinations of the different terms listed in Table 2. Our research team at King's College Hospital and King's College London screened the titles, abstracts, and full text of the resulting articles. Further literature was also included based on expert experience. Publications were finally included based on their relevance to the topics covered in this review.

\section{Clinical Efficacy Evidence in Parkinson's Disease}

\subsection{Motor Symptoms in Parkinson's Disease}

The beneficial effects of transdermal rotigotine on motor symptoms of PD (Unified PD Rating Scale [UPDRS] III score, OFF time), along with a positive impact on activities of daily life (ADL) (UPDRS II score), have been demonstrated in 11 double-blind, multicentre, phase II or III, randomized, placebo-controlled trials (RCTs) in patients with either early PD using rotigotine as monotherapy [24-29] or in patients with advanced PD and concomitant use of levodopa [30-35] (Table 3). A novel placebo-controlled trial using NMS as a primary outcome measure also showed a significant improvement in motor function, as measured by UPDRS III, and in QoL [36].

A post hoc analysis of six placebo-controlled studies $(n>2000)$ in early or advanced PD confirmed the efficacy of rotigotine on motor symptoms and ADL [37], a finding further supported by a recent review [38], two large metaanalyses [39, 40], and a prospective, multisite real-world study in more than 2000 patients with PD of varying stages and symptom severity [41]. A few open-label extension studies have also documented motor benefits lasting up to 6 years [42-45].

\section{What can be recommended?}

Although levodopa remains the gold standard of PD treatment, plenty of high-quality contemporary research appears to corroborate the use of rotigotine to alleviate motor symptoms in PD. The MDS guidelines on the management of
Table 2 The number of records found in PubMed, according to the individual search terms, published until March 2020

\begin{tabular}{|c|c|}
\hline Search term & Count \\
\hline Apathy & 6 \\
\hline Depression & 8 \\
\hline Dyskinesia & 40 \\
\hline Dysphagia & 6 \\
\hline Early morning & 15 \\
\hline Efficacy & 81 \\
\hline Elderly & 6 \\
\hline Emergency & 3 \\
\hline Fatigue & 6 \\
\hline Gastrointestinal & 6 \\
\hline Impulse control disorder & 7 \\
\hline Motor & 110 \\
\hline Non motor & 25 \\
\hline Nocturia & 0 \\
\hline Old & 11 \\
\hline Pain & 14 \\
\hline Periodic limb movement & 2 \\
\hline Perioperative management & 4 \\
\hline Restless leg syndrome & 1 \\
\hline Sleep & 34 \\
\hline Sleep disorder & 1 \\
\hline Sleep disturbance & 5 \\
\hline Tolerability & 32 \\
\hline Urinary & 1 \\
\hline Young & 5 \\
\hline Records overall & 429 \\
\hline Distinct records & 176 \\
\hline
\end{tabular}

A combination of "Parkinson Disease" [Mesh] AND rotigotine AND" and the individual search term was used to perform the search

motor symptoms in PD labelled rotigotine as "efficacious" and "clinically useful" for symptomatic monotherapy in PD, for adjunct therapy in early or stable $\mathrm{PD}$, and for management of motor fluctuations [46].

\subsubsection{Dyskinesias}

Dyskinesias are a key challenge in treating patients with PD, although recent data suggest the problem may be subsiding [47], possibly as a result of personalized therapeutic approaches such as surgery or a wider use of CDD systems [48], including rotigotine.

A post hoc analysis of two open-label extension studies of patients with early PD on rotigotine for up to 6 years indicated that the incidence of dyskinesia was lower in the absence of levodopa treatment (4 vs. 19\%) [49]. The authors of both studies independently concluded that the majority of dyskinesias developed after the addition of 
Table 3 Review of existing double-blind, randomized, placebo-controlled phase II or III trials assessing the effect of rotigotine on motor functions

\begin{tabular}{|c|c|c|c|c|c|c|c|c|}
\hline Study & Phase & Countries & $\begin{array}{l}\text { Mainte- } \\
\text { nance phase } \\
\text { (weeks) }\end{array}$ & $\begin{array}{l}\text { Rotigotine } \\
\text { dose }(\mathrm{mg} / 24 \mathrm{~h})\end{array}$ & Dosing strategy ${ }^{\mathrm{a}}$ & Sample size ${ }^{b}$ & Control group & Reference \\
\hline \multicolumn{9}{|c|}{ In early-stage Parkinson's disease } \\
\hline PATCH I/SP506 & $\mathrm{IIb}$ & USA, Canada & 7 & $2-4-6-8$ & Fixed & $206 / 242$ & Placebo & [24] \\
\hline SP512 & III & USA, Canada & 24 & $2-6$ & Optimal & $201 / 277$ & Placebo & {$[25,26]$} \\
\hline SP513 & III & $\begin{array}{l}\text { UK, Germany, } \\
\text { Israel and others }\end{array}$ & 33 & $2-8$ & Optimal & $409 / 561$ & $\begin{array}{l}\text { Ropinirole, pla- } \\
\text { cebo }\end{array}$ & [27] \\
\hline- & - & Japan & 4 & $2-16$ & Optimal & $155 / 180$ & Placebo & [29] \\
\hline $\begin{array}{l}\text { SP914/ } \\
\text { NCT01646268 }\end{array}$ & III & China & 24 & $2-8$ & Optimal & $220 / 249$ & Placebo & [28] \\
\hline \multicolumn{9}{|c|}{ In advanced-stage Parkinson's disease } \\
\hline PREFER/SP650 & III & USA, Canada & 24 & $8-12$ & Fixed & $260 / 351$ & Placebo & {$[33]$} \\
\hline $\begin{array}{l}\text { CLEOPATRA- } \\
\text { PD/SP515/ } \\
\text { NCT00244387 }\end{array}$ & III & Germany & 16 & $4-16$ & Optimal & $415 / 506$ & $\begin{array}{l}\text { Pramipexole, } \\
\text { Placebo }\end{array}$ & [34] \\
\hline $\begin{array}{l}\text { SP921/ } \\
\text { NCT00522379 }\end{array}$ & III & $\begin{array}{l}\text { USA, Chile, } \\
\text { Mexico, Peru, } \\
\text { India }\end{array}$ & 12 & $2-4-6-8$ & Fixed & $406 / 514$ & Placebo & {$[32]$} \\
\hline NCT01628848 & II & Japan & 4 & 16 & Fixed & $148 / 174$ & Placebo & [31] \\
\hline NCT01628926 & III & Japan & 4 & $2-16$ & Optimal & $354 / 420$ & $\begin{array}{l}\text { Ropinirole, Pla- } \\
\text { cebo }\end{array}$ & {$[35]$} \\
\hline $\begin{array}{l}\text { SP1037/ } \\
\text { NCT01646255 }\end{array}$ & III & China & 12 & $4-16$ & Optimal & $311 / 346$ & Placebo & {$[30]$} \\
\hline
\end{tabular}

${ }^{\mathrm{a}}$ Optimal or fixed-dose design

${ }^{\mathrm{b}}$ Subjects completed trial/subjects randomized

levodopa to rotigotine treatment [42, 43]. Although various dyskinesia variants have been proposed, diphasic dyskinesias are considered the most problematic [50], and the role of the rotigotine patch remains unclear.

\section{What can be recommended?}

Data to support the specific use of the rotigotine patch as an anti-dyskinetic agent in its own right remain scarce.

\subsection{Non-motor Symptoms in Parkinson's Disease}

NMS are an integral aspect of PD from prodromal through to palliative stages and are classified as dopaminergic or nondopaminergic, with dopaminergic NMS including those that may fluctuate with motor symptoms and representing part of the described non-motor fluctuations [51-53].

Despite the positive signals from the RECOVER study (NCT00474058) $(n=287)$, which used the Non Motor Symptoms Scale (NMSS) as an exploratory outcome measure and in which the total burden of NMS significantly improved with rotigotine [54], another RCT [36] failed to show a significant effect of rotigotine versus placebo on NMS as a whole. The different results may be due to differences in the populations studied. A post hoc analysis of the RECOVER study showed a significant effect of rotigotine for the sleep/fatigue domain of the NMSS, as well as mood and apathy, with effect sizes of $>3$ for each domain. An effect size of $>1$ was obtained for gastrointestinal symptoms (1.84) and the miscellaneous domain of the NMSS (1.16), the latter being largely driven by improvements in unexplained pain and hyperhidrosis [1].

Several double-blind RCTs explored the effects of rotigotine on non-motor functions in early and advanced PD [36, 54-57] and are summarised in Table 4.

There is also a view that motor improvement caused by dopaminergic drugs, in this case rotigotine, may exert a concurrent positive effect on NMS, thus introducing bias in our observations. However, evidence from large cohort-based linear regression analysis indicated that the effect of NMS burden on QoL in PD may be differential and does not go hand in hand with motor progression [58]. 


\subsubsection{Sleep impairment}

Nocturnal sleep disturbances, such as insomnia, nocturnal akinesia, restless legs syndrome (RLS), and others, represent common, disabling, and occasionally overlapping complaints within the multifaceted spectrum of NMS in PD [59]. During the course of the disease, $67-98 \%$ of patients with PD experience some sleep dysfunction at some point [60].

The efficacy of rotigotine compared with placebo in improving nocturnal sleep disturbances as a whole was demonstrated in three RCTs using the Parkinson's Disease Sleep Scale (PDSS) [61] or its modified version (PDSS-2) $[54,62]$. The RECOVER study was the first ever RCT to use a measurement of NMS (PDSS-2 score) as a primary outcome in patients with idiopathic PD and insufficient control of early-morning motor symptoms [54]. It offered strong evidence that rotigotine could represent a focused therapeutic strategy for several aspects of sleep-related problems, including difficulty falling asleep, breathing problems or snoring, feeling immobile during the night, or being tired/ sleepy in the morning [54]. The findings of a positive effect on sleep, particularly regarding 'difficulty falling asleep', feeling 'tired/sleepy in the morning', or 'uncomfortable in bed due to immobility', were further supported in a post hoc analysis of the study [63], with an effect size of $>3$ in the sleep/fatigue domain [1]. The benefits of transdermal

Table 4 Review of existing double-blind, randomized, placebo-controlled trials assessing the effect of rotigotine on non-motor functions in early and advanced Parkinson's disease

\begin{tabular}{|c|c|c|c|c|c|c|c|c|c|}
\hline Study & PD stage & Phase & Countries & $\begin{array}{l}\text { Mainte- } \\
\text { nance phase } \\
\text { (weeks) }\end{array}$ & $\begin{array}{l}\text { Rotigotine dose } \\
(\mathrm{mg} / 24 \mathrm{~h})\end{array}$ & $\begin{array}{l}\text { Dosing } \\
\text { strategy }^{\mathrm{a}}\end{array}$ & Sample size ${ }^{\mathrm{b}}$ & $\begin{array}{l}\text { Measurement } \\
\text { instruments }\end{array}$ & Reference \\
\hline $\begin{array}{l}\text { DOLORES/ } \\
\text { NCT01744496 }\end{array}$ & Early & IV & $\begin{array}{l}\text { USA, } \\
\text { Germany, } \\
\text { Poland, } \\
\text { Slovakia }\end{array}$ & 12 & $4-8$ & Optimal & $64 / 68$ & $\begin{array}{l}\text { Primary: LPS } \\
\text { Secondary: } \\
\text { KPSS, PDQ- } \\
\text { 8, HADS, } \\
\text { UPDRS II } \\
\text { + III }\end{array}$ & [55] \\
\hline $\begin{array}{l}\text { PD00005/ } \\
\text { NCT01782222 }\end{array}$ & $\begin{array}{l}\text { Early and } \\
\text { advanced }\end{array}$ & IV & USA, Europe & 12 & $\begin{array}{l}\leq 6 \text { or } \leq 8^{\mathrm{c}} \\
\leq 8 \text { or } \leq 16^{\mathrm{d}}\end{array}$ & Optimal & $99 / 122$ & $\begin{array}{l}\text { Primary: AS } \\
\text { Secondary: } \\
\text { AS, PDQ-8, } \\
\text { NMSS, } \\
\text { SHAPS, } \\
\text { CGI I }\end{array}$ & [56] \\
\hline $\begin{array}{l}\text { SP0976/ } \\
\text { NCT01300819 }\end{array}$ & $\begin{array}{l}\text { Early and } \\
\text { advanced }\end{array}$ & IV & Europe & 12 & $\begin{array}{l}\leq 8^{\mathrm{c}} \\
\leq 16^{\mathrm{d}}\end{array}$ & Optimal & $283 / 349$ & $\begin{array}{l}\text { Primary: } \\
\text { NMSS } \\
\text { Secondary: } \\
\text { UPDRS, } \\
\text { PDQ-39, } \\
\text { NMSS }\end{array}$ & [36] \\
\hline $\begin{array}{l}\text { SP1041/ } \\
\text { NCT01523301 }\end{array}$ & $\begin{array}{l}\text { Early and } \\
\text { advanced }\end{array}$ & IV & South Korea & 8 & $2-8$ & Optimal & $313 / 380$ & $\begin{array}{l}\text { Primary: } \\
\text { HAM-D } \\
\text { Secondary: } \\
\text { BDI-II, AS, } \\
\text { UPDRS II + } \\
\text { III, SHAPS }\end{array}$ & [57] \\
\hline $\begin{array}{l}\text { RECOVER/ } \\
\text { NCT00474058 }\end{array}$ & $\begin{array}{l}\text { Early and } \\
\text { advanced }\end{array}$ & III & $\begin{array}{l}\text { USA, Europe, } \\
\text { Oceania, } \\
\text { South Africa }\end{array}$ & 4 & $2-16$ & Optimal & $246 / 287$ & $\begin{array}{l}\text { Primary: } \\
\text { UPDRS III, } \\
\text { PDSS } \\
\text { Secondary: } \\
\text { NADCS }\end{array}$ & [54] \\
\hline
\end{tabular}

AS Apathy Evaluation Scale, BDI-II Beck Depression Inventory, CGI Clinical Global Impression Scale (item 1-severity of illness), HADS Hospital Anxiety and Depression Scale, HAM-D Hamilton Depression Scale, KPSS King's PD Pain Scale, LPS 11-point Likert pain scale, NADCS Nocturnal Akinesia Dystonia and Cramps Score, NMSS Nonmotor Symptoms Scale, $P D$ Parkinson's disease, $P D Q-39$ 39-item Parkinson's Disease Questionnaire, $P D Q-8$ 8-item Parkinson's Disease Questionnaire, PDSS Parkinson's Disease Sleep Scale, SHAPS Snaith Hamilton Pleasure Scale, UPDRS Unified Parkinson's Disease Rating Scale (part II—activities of daily living; part III—motor symptoms)

${ }^{a}$ Optimal or fixed-dose design

${ }^{\mathrm{b}}$ Subjects completed trial/subjects randomized

${ }^{\mathrm{c}}$ Group of patients not receiving levodopa

${ }^{\mathrm{d}}$ Group of patients receiving levodopa 
rotigotine on sleep disturbances appeared to be sustained for up to 1 year in an open-label study that included 84 completers of the RECOVER study [45].

Sleep fragmentation as measured with the PDSS-2 [64], and self-reported improvement of sleep quality as assessed by PDSS item 1 [65], the Non-Motor Symptoms Questionnaire (NMSQ) [66], or the Pittsburgh Sleep Quality Index [67], improved with rotigotine therapy in open-label studies or studies performed in routine clinical practice settings. There have also been indications that rotigotine might be effective on early-morning off (EMO) symptoms (Sect. 3.3.2).

One of the above-mentioned RCTs also documented a significant improvement in polysomnography parameters (increased sleep efficiency and REM sleep; reduced sleep onset latency and wakefulness) [61]. Researchers from an open-label pilot study suggested that improvements in perceived sleep quality after rotigotine treatment was at least partly mediated by a reduction in motor activity during sleep, as confirmed by actigraphic recordings [68]. The beneficial effect of rotigotine on sleep impairment was further corroborated in an open-label study in which patients with PD were assessed using both objective (video-polysomnography) and subjective (Epworth Sleepiness Scale, PDSS-2) approaches [69]. Therefore, some justification does exist of the notion that rotigotine can improve aspects of sleep in $\mathrm{PD}$, not just by improving nocturnal motor intrusions but also through modification of intrinsic properties related to sleep structure and thus sleep fragmentation, a major source of subjective nocturnal complaints in PD during the course of the disease, right from the early stages.

\section{What can be recommended?}

High-quality evidence from original studies underlines the beneficial effect of rotigotine on various aspects of sleep impairment in PD, spanning from motor to non-motor benefits, including a possible effect on sleep architecture [70]. Therefore, rotigotine was recently labelled "possibly useful" for the treatment of insomnia in PD and "likely efficacious" and "possibly useful" in improving sleep by the MDS-EBM committee [9].

\subsubsection{Pain}

Pain is a bothersome and multifactorial NMS of PD, with a frequency ranging from 40 to $85 \%$ [71, 72], and whose management is regarded as a key unmet need [73]. Pain has partly a dopaminergic basis, and management of fluctuationrelated pain can be assisted by optimization of dopaminergic therapy $[73,74]$.

In the RECOVER study, rotigotine compared with placebo showed a significant beneficial effect on both nocturnal pain (as measured with the PDSS-2, item 10) and general pain (as measured with the Likert pain scale) [54]. These results were further confirmed in a post hoc analysis of the RECOVER study [71]; significant effects of rotigotine on nocturnal pain were also corroborated in a large open-label study based on the use of PDSS-2 and a pain visual analogue scale [75].

The DOLORES study remains the only RCT to have addressed pain and dopaminergic therapy in PD. Its findings supported the beneficial effects on fluctuation-related pain in patients with PD receiving rotigotine, measured with the King's Parkinson's Pain Scale [55].

\section{What can be recommended?}

The MDS-EBM committee agreed that evidence is currently insufficient to define the efficacy of rotigotine on pain in PD [9], although rotigotine and oxycodone-naloxone remain the only two drugs for which a high level of evidence for PD and pain management is available. From a pragmatic point of view, there exists reasonable evidence to support the use of rotigotine in the management of fluctuation (off)-related pain and nocturnal pain $[55,70,71]$.

\subsubsection{Fatigue}

In general, fatigue is a challenging, troublesome, and common NMS of PD that is typified by excessive tiredness and a feeling of debilitation or exhaustion independent of physical activity [76, 77]. A post hoc analysis of the RECOVER study showed a benefit in the NMSS 'sleep/fatigue' domain (effect size $>3$ ) in the group receiving rotigotine compared with placebo, also augmented by a significant improvement of the individual NMSS item 'fatigue (tiredness) or lack of energy' in patients receiving rotigotine compared with placebo. The percentage of patients who experienced some degree of fatigue (NMSS item score $>0$ ) improved from $77 \%$ at baseline to $60 \%$ at the end of treatment in the rotigotine group compared with no improvement in the placebo group [1].

These results are consistent with data from several other studies that suggested a benefit in the NMSS domain 'sleep/ fatigue' or the Fatigue Severity Scale in patients with PD receiving rotigotine compared with a control group [36, 54, 56]. However, until a study using a validated fatigue-specific scale shows a positive effect of rotigotine, its effects on fatigue cannot be certain.

\section{What can be recommended?}

In patients with $\mathrm{PD}$ with fatigue, the transdermal rotigotine patch could be considered as a therapeutic option with a multimodal action and a potential benefit on comorbidities 
of fatigue, such as mood impairment, pain, and aspects of sleep dysfunction [78].

\subsubsection{Depression}

Depression is one of the most common psychiatric disorders in PD, with a global prevalence of $40-50 \%$, and it complicates PD from the prodromal through to the palliative stage [79]. The RECOVER study showed that the rotigotine transdermal patch $2-16 \mathrm{mg} / 24 \mathrm{~h}$ may be beneficial for patients with PD with low mood as measured by the Beck Depression Inventory-II (BDI-II) and the mood/ apathy domain (effect size $>3$ ) of the NMSS $[1,54]$. Stable improvements in the mood/apathy domain have also been observed in the 1-year open-label extension study [45]. These findings were replicated by the first RCT to use changes in NMSS total score as a primary outcome, although the latter did not reach statistical significance [36]. In addition, a significant improvement in the mood/ apathy domain was also described in a Spanish observational multicentre study [66]. A recent meta-analysis of eight RCTs $(n=1675)$ suggested that the use of the rotigotine transdermal patch was associated with improved psychiatric conditions, including depression, as measured by the depression/apathy domain of NMSS and the BDI-II. Given rotigotine's high affinity for the $\mathrm{D}_{3}$ receptor and the associated function in the limbic circulation, emotional disorders associated with PD may improve [80]. On the other hand, a South Korean RCT of 380 patients showed no change in the 17-item Hamilton Depression Rating Scale outcome, whereas significant improvements in motor scores were observed with rotigotine versus placebo [57]. Recently, the MDS-EBM committee defined the use of the rotigotine transdermal patch for the treatment of depression in PD as "unlikely efficacious" [9].

\section{What can be recommended?}

In patients with $\mathrm{PD}$, the rotigotine transdermal patch should not be considered as a first choice to manage depression. However, rotigotine could be considered as a treatment option with a multimodal action in managing both motor dysfunction and depression in relation to personalising treatment and avoiding the use of additional antidepressants in selected cases.

\subsubsection{Apathy}

Apathy is widely recognised as an individual symptom of PD and can be distinguished from other PD-related psychiatric symptoms and personality traits [81, 82]. Apathy is described as a decline in goal-oriented behaviour and cognition and in emotional expression, with a reported pooled prevalence of 39.8\% [83]. However, it has not been assessed as a primary outcome in clinical studies [78].

Post hoc analysis of the RECOVER study showed a beneficial effect in the 'mood/ apathy' domain of the NMSS in favour of rotigotine $(n=178)$ compared with placebo $(n=89)$ and a significant improvement in the following four of the seven individual items included in this domain: 'lost interest in surroundings', 'lost interest in doing things', 'seems sad or depressed', and 'difficulty experiencing pleasure' [1]. Although the study did not show a statistically significant difference between rotigotine treatment and placebo in the NMSS total score, it did show a positive effect of rotigotine treatment in the NMSS domain 'mood/apathy' [36].

Nevertheless, a multicentre RCT showed no relevant improvement of apathy in the three groups (low-dose rotigotine, $n=41$; high-dose rotigotine, $n=41$; and placebo, $n=40$ ), as measured by the self-rated Apathy Scale (AS) [56]. However, an improvement in the NMSS 'mood/apathy' domain in the rotigotine groups was observed, and a post hoc analysis showed a benefit in favour of rotigotine considering the following four individual items: 'lost interest in surroundings', 'lost interest in doing things', 'has flat moods', 'difficulty experiencing pleasure' [56].

Moreover, a meta-analysis of eight RCTs examined the effect of the transdermal rotigotine patch on neuropsychiatric symptoms in $\mathrm{PD}$ and reported that the emotion/apathy domains of the BDI-II, the AS, the 8-item Parkinson's disease Questionnaire (PDQ-8), and the NMSS significantly improved in patients with $\mathrm{PD}$ receiving rotigotine compared with those receiving placebo [80]. The authors concluded that treatment with the rotigotine transdermal patch was effective at improving neuropsychiatric symptoms and QoL in patients with PD.

\section{What can be recommended?}

The MDS-EBM committee classified rotigotine as "unlikely efficacious" for the treatment of apathy in PD [9]. However, some studies did indicate a benefit of the transdermal rotigotine patch on apathy $[1,36,80]$. If patients with PD are experiencing apathy, the rotigotine transdermal patch is a treatment option that may be considered.

\subsubsection{Nocturia and urinary dysfunction}

Urinary symptoms, as part of the NMS spectrum, represent a significant factor in reducing QoL and increasing morbidity in patients with PD [84]. Among them, nocturia is a common complaint, with a reported prevalence ranging from 34.6 to 86\% [85]. A Spanish observational, retrospective, multisite study reported a positive effect from rotigotine on urinary function and urgency in patients with PD [66], whereas a 
few open-label either observational or routine clinical practice studies found that nocturia in particular improved with rotigotine [64, 65, 68, 86]. However, specific and detailed studies are still needed so these findings can be translated into clinical practice.

\section{What can be recommended?}

For the time being, rotigotine cannot be recommended for urinary dysfunction or nocturia treatment in PD. However, if there are any indications that the patient experiences off or EMO-related nocturia, then treatment with rotigotine may be recommended as it is one of only a few drugs to have shown an effect on nocturia.

\subsubsection{Gastrointestinal symptoms}

In patients with $\mathrm{PD}$, a spectrum of gastrointestinal tract (GIT) conditions, such as dysphagia (Sect. 3.3.1), gastroparesis [87], gastroenteritis [88] or Helicobacter pylori infection $[89,90]$, can alter the intake or absorption of oral anti-PD drugs.

An observational study suggested that switching from conventional oral therapy to the rotigotine transdermal patch offers a significant advantage by reducing existing GIT symptoms, such as heartburn, bloating, nausea, abdominal pain, vomiting, or diarrhoea [87]. Using a simple non-oral transdermal therapy has inherent advantages in circumstances when the effects of oral therapies may become erratic because of limitations in oral absorption [11]. However, the specific effects of rotigotine on a range of GIT symptoms need to be further investigated in controlled clinical trials.

\section{What can be recommended?}

Transdermal applications have the distinct advantages of bypassing factors that may influence the absorption of oral medication as they enter directly into the systemic circulation and avoid the 'first pass' liver effects [17]. Use of rotigotine for the management of specific GIT symptoms cannot be recommended at present.

\subsection{Non-motor and Motor Symptoms}

\subsubsection{Dysphagia and Drooling}

More than $80 \%$ of patients with PD have difficulty swallowing [91, 92], which could lead to malnutrition and aspiration pneumonia, a potentially fatal complication [93-95]. Dysphagia is partly dopaminergic [96], and a small retrospective open-label study of six subjects showed a significant improvement of dysphagia, as assessed by video-fluoroscopy (both oral and pharyngeal phase) with rotigotine [97].

Sialorrhea has been reported in 10-84\% of patients with $\mathrm{PD}$ as a bothersome symptom that is associated with social isolation and reduced QoL [98-100]. A retrospective analysis $(n=728)$ reported drooling in one-third of patients with moderately advanced PD [101]. An open-label pilot study in seven subjects indicated a beneficial effect from rotigotine on drooling [102].

\section{What can be recommended?}

We encourage the investigative use of the rotigotine transdermal patch as a possible therapeutic option for patients with PD with dysphagia with or without drooling. In many UK hospitals, rotigotine is already recommended as the treatment of choice for patients with PD with severe dysphagia or those who are to receive nil by mouth because of surgical procedures or acute illness. This strategy is clinically useful [88] and to be recommended. Large-scale studies of the acceptability and efficacy of rotigotine use in dysphagic PD are advisable.

\subsubsection{Early-Morning Off}

Typically, off-related phenomena develop over time in patients with PD receiving chronic levodopa therapy and have initially been perceived as motor symptoms only [103, 104]; however, recent research has highlighted the key importance of non-motor off phenomena and non-motor fluctuations [52].

EMO periods have been identified as a significant cause of disability in patients with PD [105], especially in those with advanced motor symptoms [106]. A European multicentre observational study $(n=320)$ exploring the extent of NMS during EMO showed that the most frequently experienced NMS during EMO periods were anxiety, low mood, paraesthesia, pain, dribbling of saliva, and urinary urgency. The study sub-cohort treated only with the rotigotine transdermal patch exhibited a significantly lower rate of EMO and had the highest rate of EMO-free patients, even compared with other prolonged-release DAs [106].

RECOVER was the first RCT to explore early-morning motor function as a co-primary outcome in patients with PD; results indicated that rotigotine treatment may significantly reduce early-morning motor off periods [54].

Finally, an open-label study (NCT00243945) $(n=54)$ assessed the clinical efficacy of the rotigotine transdermal system in patients with PD with EMO and sleep disorders and reported improvement of early-morning motor parameters as measured with UPDRS III scores [86]. 


\section{What can be recommended?}

The rotigotine transdermal patch should be considered the first option for management of troublesome early-morning dystonia and off symptoms.

\section{Restless Legs Syndrome and Periodic Limb Movement Disorder}

\subsection{Restless Legs Syndrome}

RLS, also known as Willis-Ekbom disease (WED), is regarded as the most common movement disorder, as it occurs in $2.5-10 \%$ of adults in the general population and is even more frequent in patients with PD (10-50\%) [107].

The rotigotine transdermal patch is effective for RLS/ WED in PD, as shown in five open-label studies [64, 67-69, 75] and a RCT [54]. In the RECOVER study, the use of the rotigotine transdermal patch $2-16 \mathrm{mg} / 24 \mathrm{~h}$ was associated with a significant improvement in RLS as measured by the specific items of the PDSS- 2 when compared with placebo [54].

Finally, as short-acting dopaminergic treatment can lead to the development of augmentation syndrome, one of the most common and troublesome complications related to chronic dopaminergic treatment in RLS/WED, the rotigotine transdermal patch could be preferred as it offers the advantage of CDD [108].

\subsection{Periodic Limb Movement Disorder}

Periodic limb movement disorder (PLMD) is a sleep disorder characterised by excessive involuntary and periodic movements of the limbs during sleep, leading to arousals, sleep fragmentation, and subsequent excessive daytime sleepiness [109]. It is often, but not always, associated with RLS/WED and also commonly observed in patients with PD [110].

One open-label study confirmed the efficacy of the rotigotine transdermal patch in reducing periodic limb movements as measured by video PSG recordings [69] in patients with PD.

\section{What can be recommended?}

The relevance of PLMD in PD is questionable and unclear. These studies have not specifically investigated the effects of rotigotine on RLS in PD. As such, in spite of the attenuation of PLMD, rotigotine cannot specifically be recommended for PD-RLS at this stage, although it is classified as efficacious for RLS [108].

\section{Use in Specific Clinical Scenarios}

\subsection{Nil by Mouth}

Rotigotine is the preferred option in nil-by-mouth strategies for acutely ill patients who may not be able to swallow, pre-/post-surgically, or during emergencies or perioperative management $[111,112]$.

\subsection{Perioperative Management}

A prospective open-label study ( $n=14$; NCT00594464) supported the rotigotine transdermal patch as a feasible alternative to oral medication in perioperative management, both by patients and physicians, even in patients receiving more than one anti-PD drug [113]. This study reported a high acceptance of the patch among patients, most of whom would select this treatment again for future surgery. Data suggest that switching from oral DAs to rotigotine can be done safely, even overnight [114], and published data imply that the delivery of rotigotine is not affected by surgery and that the applied doses and plasma levels remain within the desired range $[111,115]$. A post hoc analysis of a non-interventional study $(n=$ 91) showed that almost half of patients who switched to rotigotine from another DA because of insufficient efficacy felt their symptoms had improved [116].

A proposed algorithm to guide the selection and dosage of rotigotine during perioperative treatment could be based on the adjusted levodopa equivalent daily dosage (LEDD). If the dose is lower than $350 \mathrm{mg} /$ day, rotigotine therapy could be preferable, otherwise subcutaneous apomorphine is recommended [117].

\subsection{Use for Emergencies}

A shift in dopaminergic therapy is a major cause of emergencies in patients with PD and can aggravate motor symptoms or cause severe non-motor complications, including psychosis [112]. Abrupt discontinuation, inappropriate dosing, or dose omission of anti-PD medication can cause serious, potentially fatal complications, including an akinetic crisis $[111,118]$. Parkinsonism-hyperpyrexia syndrome (PHS) can be one such complication and manifests as an acute 'akinetic attack' with an incidence rate of $0.3 \%$ and a mortality rate of $4 \%[112,119,120]$. One treatment option for PHS is increasing the oral levodopa dose. If this proves ineffective, the rotigotine patch may be considered to further escalate dopaminergic treatment [112]. 
What Can be Recommended in Specific Clinical Scenarios?

The rotigotine transdermal patch is a major part of many nil-by-mouth strategies, may optimise treatment management during hospitalization, and could be beneficial in emergency situations or intensive care environments in addition to levodopa. Its non-invasive, once-daily, transdermal application ensures a CDD under demanding circumstances. In this context, rotigotine played an important role in strategies applied to manage patients with PD with coronavirus disease 2019 (COVID-19) infections who were acutely ill and needed dopaminergic therapies to avoid DA withdrawal syndrome (DAWS).

\section{Dual-Agent Dopamine Receptor Agonist Therapy with Advanced Therapies}

The combination of drugs with different pharmacokinetic/ pharmacological profiles may enable the use of lower dosages and be better tolerated. This becomes particularly interesting as overnight control of PD symptoms can be difficult [121]. The use of the rotigotine transdermal patch overnight in combination with advanced therapies represents a valid therapeutic strategy to provide 24-h treatment but with strict specialist monitoring. The combination of daily apomorphine subcutaneous infusion and rotigotine transdermal patch overnight was safe and useful in the management of PD symptoms, particularly sleep and mood impairment, at a 2-year follow-up [122]. Similarly, the overnight use of a rotigotine transdermal patch can be effective in controlling night-time symptoms in patients with PD on intrajejunal levodopa carbidopa gel (LCIG) infusion, particularly in countries where the use of a single LCIG cassette per day is recommended so that associated costs can be contained [123].

\section{Older Age PD Population}

Older participants are frequently under-represented in PD research [124]. However, the safety profile of the transdermal rotigotine patch appeared relatively unaffected by increasing age in a double-blind RCT, suggesting that rotigotine should be considered as an adjunct therapy in elderly patients (upper limit of 75 years) with PD [31]. Two observational prospective studies, one with [116] and one without a control group [125], demonstrated that rotigotine was relatively well-tolerated in older patients with PD (upper limit of 70 and 75 years, respectively), without any alerting safety issues. Although the former study reported more adverse effects (AEs) in the older group, improvement between age groups was similar for the secondary effectiveness variable of PDSS-2 [116], and the beneficial effect of rotigotine in the latter study was mostly related to the reduction of nocturnal symptoms [125]. The idea that rotigotine is relatively well-tolerated and effective in patients with PD aged $>75$ or even 80 years was further supported by a retrospective study and two post hoc analyses of up to four RCTs [126-128], with no major differences in the maintenance dosage of the drug [128]. Finally, a recent study in a real-life setting in which $31.5 \%$ of participants were aged $>75$ years assessed the safety of longacting and transdermal DAs and reported a tolerability of $84.4 \%$ in patients receiving rotigotine. This study showed no significant differences in tolerability between younger and older patients with PD [129].

\section{What can be recommended?}

Advanced age alone should not be perceived as a contraindication to rotigotine administration. Rotigotine was generally well-tolerated in older patients [125, 127, 128]. We consider rotigotine as a beneficial option, especially if no other DA can be given [130].

\section{Caregiver Aspect}

A cross-sectional, non-interventional study assessing the attitudes of caregivers/nurses $(n=128)$ and physicians $(n$ $=41$ ) to the transdermal patch showed a significant benefit in the care of patients with PD in everyday situations and when undergoing medical treatment when the rotigotine transdermal patch was an additional therapy compared with oral medication [131]. The burden on caregivers and the workload for drug management in the care of patients with PD could be reduced with the simple once-daily application of the rotigotine transdermal patch.

\section{Impulse Control Disorders}

Impulse control disorders (ICDs) in PD refer to a wide range of abnormal behaviours, including but not limited to pathological gambling, compulsive shopping, punding, hypersexuality, and compulsive eating. ICDs vary in severity; are associated with reduced QoL, functional impairment, and increased caregiver burden; and are widely associated with the use of DAs [132]. The DOMINION study reported at least two ICDs in $3.9 \%$ of patients with PD [133]. However, among other DAs, rotigotine seemed less likely to trigger ICDs. An international observational multicentre survey $(n=425)$ exploring ICD behaviour in patients with PD receiving short- and long-acting DAs reported an overall ICD rate of $13.4 \%$ [134]. Among them, 
rotigotine had the lowest ICD rate of $4.9 \%$, with hypersexuality being the most frequently reported ICD. Another multicentre cross-sectional study $(n=233)$ [135] drew the same conclusions.

These data were further supported by a post hoc analysis of six open-label extension studies $(n=786$; covering a minimum of 6 months), which examined ICD-related behaviours with the long-term use of rotigotine in $\mathrm{PD}$ [132] and reported a mostly mild to moderate ICD rate of $9.0 \%$. Overall, an ICD rate of $5-9 \%$ could be inferred for rotigotine, which is lower than other conventional oral DAs [132, 134]. It has been suggested that rotigotinerelated ICDs may occur after prolonged use, even after a few years, so continued monitoring is important [132]. Additionally, a review on the management of ICDs in PD indicated that, although switching from an oral DA to transdermal rotigotine may be considered as a treatment option, rotigotine may still lead to the occurrence of ICDs [136]. The same review indicated that the change in drug adjustment might be beneficial as the patch may be administered at a lower equivalent dose.

\section{What can be recommended?}

Rotigotine is considered the least likely DA to cause ICDs. Therefore, it should be regarded as the first option among DAs, especially in patients with an ICD history or where DAWS [137] is a possibility. If a patient is already taking other DAs and is experiencing ICDs, a switch to rotigotine could be considered if there is a clinical need to continue DAs.

\section{Tolerability and Side Effects}

Several studies, including double-blind RCTs, have reported that the rotigotine transdermal patch is generally well-tolerated [25, 32-34, 54-56, 64, 86, 87, 116, 138].

AEs linked to rotigotine use are reported to be similar to those observed with other DAs, plus the application site reactions of the transdermal patch (Fig. 2) [38]. Long-term studies have reported that application site reactions were the most common treatment-emergent AEs. The majority of these AEs have been mild to moderate in intensity and mostly subsiding quickly after patch removal [139].

\section{Rotigotine and Delayed Start Therapy}

In animal models, a potential neuroprotective effect of rotigotine has been shown through upregulation of metallothionein expression in astrocytes by targeting $5-\mathrm{HT}_{1 \mathrm{~A}}$ receptors [140]. There is no clinical evidence of neuroprotection with rotigotine at this time. However, a post hoc analysis of the RCTs SP512 and SP513 and their corresponding open-label extension studies, SP702 and SP716, testing the impact of initiating rotigotine treatment 6 months earlier in a group of patients with early-stage PD compared with a delayed start in another group with similar characteristics [141] showed that earlier treatment may lead to a slower return to baseline mean UPDRS II and III scores. The authors concluded that introducing rotigotine in patients with PD with no or mild functional disruption may lead to long-term clinical benefits, but clearly this post hoc data-based conclusion would need replication in prospective controlled studies.
Fig. 2 Percentage of patients (range from minimum to maximum; grey line) with emergent adverse events from rotigotine transdermal patch treatment in phase II and III clinical trials. Data for hallucinations, peripheral oedema, orthostatic hypotension, and sleep attacks occurred generally up to the given value, no ranges shown (data extracted from a review [38])

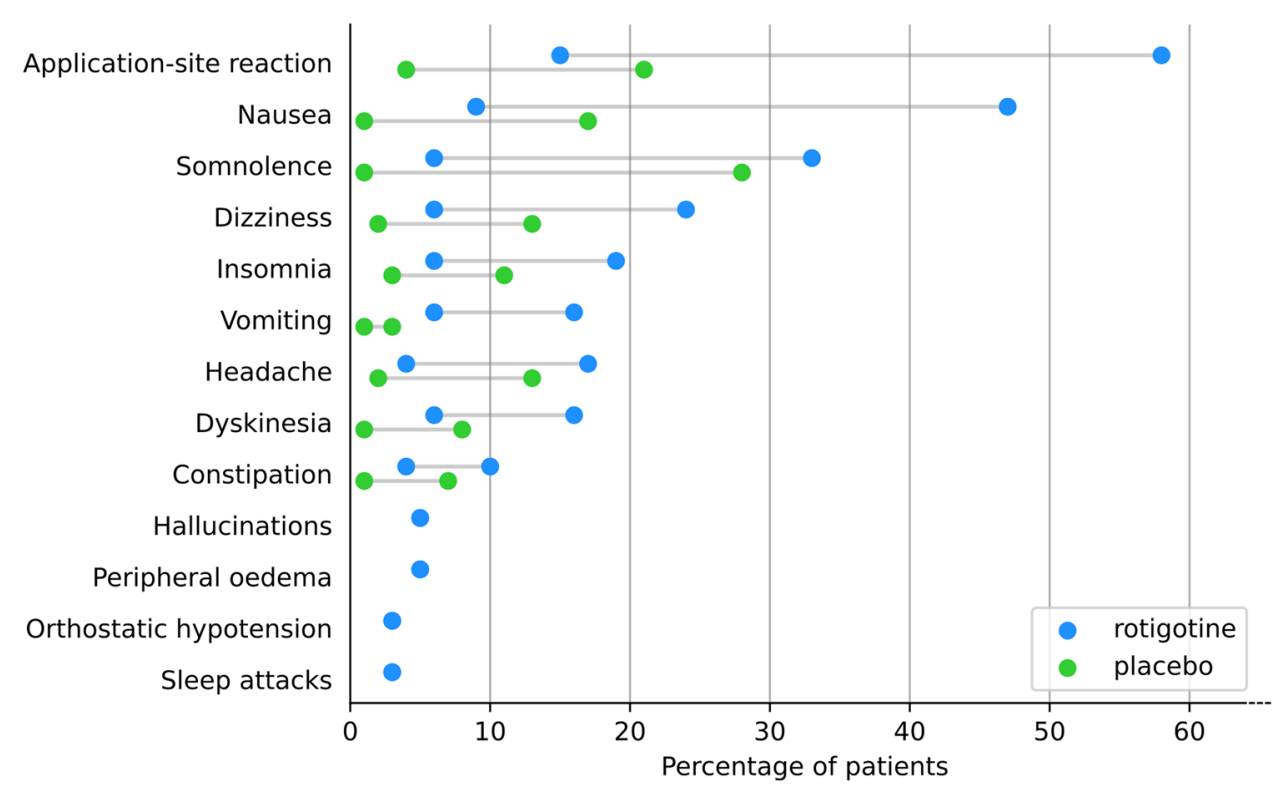



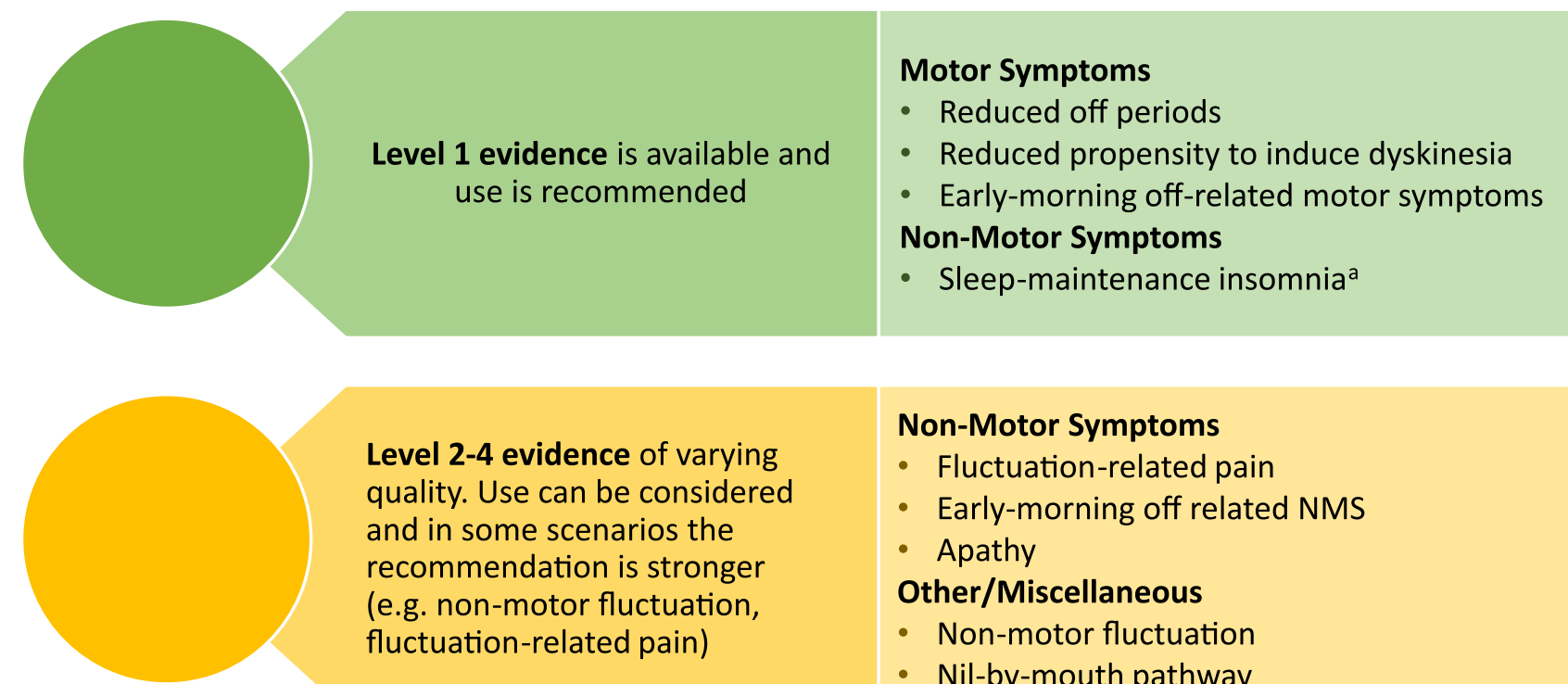

Non-Motor Symptoms

- Fluctuation-related pain

- Early-morning off related NMS

- Apathy

\section{Other/Miscellaneous}

- Non-motor fluctuation

- Nil-by-mouth pathway

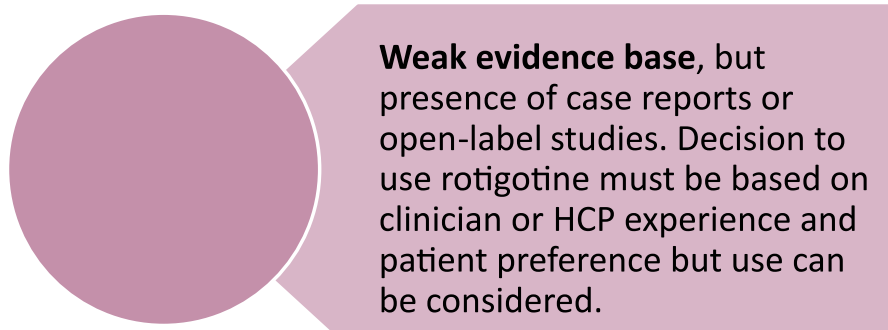

Non-Motor and Motor Symptoms

- Dysphagia

Other/Miscellaneous

- Perioperative management

- Use in impulse control disorder

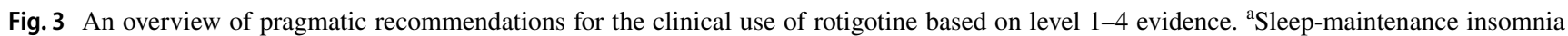
= causes including early morning off. $H C P$ healthcare professional, NMS non-motor symptoms

\section{Conclusion}

The rotigotine transdermal patch is a conventional treatment strategy for PD and RLS. It provides an impressive array of non-motor benefits in addition to its motor benefits, which are non-inferior to those of other conventional DAs (Fig. 3). Rotigotine offers a CDD pattern, particularly compared with oral dopaminergic therapies, with a good tolerability profile. The rotigotine transdermal patch has shown a positive effect on the treatment of motor intrusions during nocturnal sleep and EMO. Its efficacy for fluctuation-related pain, apathy, and depression are often not clinically realised or used. Although level 1 evidence for 'pain' and 'apathy' is lacking, which led the MDSEBM committee to classify rotigotine as "investigational" for pain and "unlikely efficacious" for apathy, overall data and experience suggest that the patch can reduce fluctuation-related pain and apathy. In addition, the transdermal rotigotine patch could be considered as a beneficial option for treating comorbidities of fatigue.
New potential approaches for rotigotine delivery are being investigated, such as rotigotine-loaded polymer micelles thermosensitive hydrogels or rotigotine-loaded chitosan nanoparticles in nose-to-brain delivery models $[142,143]$, with the latter approach showing potential neuroprotective effects in human neuroblastoma cell lines [143]. Furthermore, subcutaneous injections of polymer-linked rotigotine were examined in an open-label study with patients with PD $(n=19)$ and showed stable dose-related plasma levels with good tolerability when applied once weekly [144].

From a theoretical point of view, the role of the rotigotine patch may also be of interest in the current COVID19-related healthcare crisis. Acutely ill patients with PD, who may be receiving nil by mouth or unable to swallow, would often rely on the rotigotine transdermal patch to receive dopaminergic therapy. This strategy has been used successfully in a handful of cases of patients with PD with COVID-19 infections in the UK. When used with clear and tangible indications, the rotigotine patch offers a reasonable 
direction to deliver personalised medicine for PD and RLS in a real-life setting.

\section{Declarations}

Funding The authors did not receive support from any organization for the submitted work. The open access fee was covered by the Department of Research and Innovation at King's College Hospital London, UK

Conflict of interest Vanessa Raeder has no conflicts of interest. Iro Boura reports a congress grant from UCB, outside the submitted work. Valentina Leta reports personal fees from Britannia Pharmaceuticals, personal fees from Invisio Pharmaceuticals, grants from Parkinson's UK, grants from Bial, outside the submitted work. Peter Jenner reports consultancies and Advisory Boards for Abbvie, Bial, Eisai, Kyowa Kirin, Lundbeck, FP Pharmaceuticals, Profile Pharma, UCB, Worldwide Clinical Trials, Zambon, outside the submitted work. Heinz Reichmann was acting on Advisory Boards, gave lectures and received research grants from Abbott, Abbvie, Bayer Health Care, Bial, Boehringer/Ingelheim, Brittania, Cephalon, Desitin, GSK, Lundbeck, Medtronic, Merck-Serono, Novartis, Orion, Pfizer, TEVA, UCB Pharma, Valeant, and Zambon, outside the submitted work. Lisa Klingelhoefer reports academic grants from EU Horizon 2020; habilitation funding for women from the Medical Faculty of the Technical University Dresden, Germany; research support by the university of excellence of TU Dresden funded by the excellence strategy of the federal and state governments (Str1911_038) without any influence on scientific contents, outside the submitted work. Claudia Trenkwalder reports grants from Britannia, Roche, M.J. Fox (European grant: program Horizon 2020), UCB, Gruenenthal, Otsuka, outside the submitted work. K. Ray Chaudhuri reports advisory board for AbbVie, UCB, GKC, Bial, Cynapsus, Novartis, Lobsor, Stada, Medtronic, Zambon, Profile, Sunovion, Roche, Theravance, Scion, Britannia; honoraria for lectures from AbbVie, Britannia, UCB, Mundipharma, Zambon, Novartis, Boeringer Ingelheim; grants (Investigator Initiated) from Britania Pharmaceuticals, AbbVie, UCB, GKC, Bial; academic grants from EU, IMI EU, Horizon 2020, Parkinson's UK, NIHR, PDNMG, EU (Horizon 2020), Kirby Laing Foundation, NPF, MRC, Wellcome Trust, outside the submitted work.

Availability of data and material Data sharing not applicable to this article as no datasets were generated or analysed during the current study.

Ethics approval Not applicable.

Consent to participate Not applicable.

Consent for publication Not applicable.

Code availability Not applicable.

Author contributions KRC conceived of the idea. VR, IB, VL performed the literature search. VR, IB, VL and KRC wrote the first draft of the paper. All authors critically revised the manuscript. All authors read and approved the final manuscript.

Open Access This article is licensed under a Creative Commons Attribution-NonCommercial 4.0 International License, which permits any non-commercial use, sharing, adaptation, distribution and reproduction in any medium or format, as long as you give appropriate credit to the original author(s) and the source, provide a link to the Creative
Commons licence, and indicate if changes were made. The images or other third party material in this article are included in the article's Creative Commons licence, unless indicated otherwise in a credit line to the material. If material is not included in the article's Creative Commons licence and your intended use is not permitted by statutory regulation or exceeds the permitted use, you will need to obtain permission directly from the copyright holder. To view a copy of this licence, visit http://creativecommons.org/licenses/by-nc/4.0/.

\section{References}

1. Chaudhuri KR, Martinez-Martin P, Antonini A, Brown RG, Friedman JH, Onofrj M, et al. Rotigotine and specific nonmotor symptoms of Parkinson's disease: post hoc analysis of RECOVER. Parkinsonism Relat Disord. 2013;19:660-5.

2. Kuhlman GD, Flanigan JL, Sperling SA, Barrett MJ. Predictors of health-related quality of life in Parkinson's disease. Parkinsonism Relat Disord. 2019;65:86-90.

3. Nicoletti A, Mostile G, Stocchi F, Abbruzzese G, Ceravolo R, Cortelli $\mathrm{P}$, et al. Factors influencing psychological well-being in patients with Parkinson's disease. PLoS ONE. 2017;12:1-8.

4. Martinez-Martin P, Rodriguez-Blazquez C, Kurtis MM, Chaudhuri KR. The impact of non-motor symptoms on health-related quality of life of patients with Parkinson's disease. Mov Disord. 2011;26:399-406.

5. Titova N, Chaudhuri KR. Non-motor Parkinson disease: new concepts and personalised management. Med J Aust. 2018;208:404-9.

6. Schapira AHV, Chaudhuri KR, Jenner P. Non-motor features of Parkinson disease. Nat Rev Neurosci. 2017;18:435-50.

7. Hurt CS, Rixon L, Chaudhuri KR, Moss-Morris R, Samuel M, Brown RG. Identifying barriers to help-seeking for non-motor symptoms in people with Parkinson's disease. J Health Psychol. 2019;24:561-71.

8. Chaudhuri KR, Prieto-Jurcynska C, Naidu Y, Mitra T, FradesPayo B, Tluk S, et al. The nondeclaration of nonmotor symptoms of Parkinson's disease to health care professionals: an international study using the nonmotor symptoms questionnaire. Mov Disord. 2010;25:704-9.

9. Seppi K, Chaudhuri KR, Coelho M, Fox SH, Katzenschlager $\mathrm{R}$, Perez Lloret $\mathrm{S}$, et al. Update on treatments for nonmotor symptoms of Parkinson's disease-an evidence-based medicine review. Mov Disord. 2019;34:180-98.

10. National Institute for Health and Care Excellence. Parkinson's disease in adults. NICE guideline (NG71). NICE Guidel. 2017.

11. Chaudhuri KR, Qamar MA, Rajah T, Loehrer P, Sauerbier A, Odin P, et al. Non-oral dopaminergic therapies for Parkinson's disease: current treatments and the future. NPJ Park Dis. 2016;2:16023.

12. Jenner P. A novel dopamine agonist for the transdermal treatment of Parkinson's disease. Neurology. 2005;65:S3-5.

13. Wood M, Dubois V, Scheller D, Gillard M. Rotigotine is a potent agonist at dopamine D1 receptors as well as at dopamine D2 and D3 receptors. Br J Pharmacol. 2015;172:1124-35.

14. Chen JJ, Swope DM, Dashtipour K, Lyons KE. Transdermal rotigotine: a clinically innovative dopamine-receptor agonist for the management of Parkinson's disease. Pharmacotherapy. 2009;29:1452-67.

15. Todorova A, Chaudhuri KR. Subcutaneous, intranasal and transdermal dopamine agonists in the management of Parkinson's disease. In: Galvez-Jimenez N, Fernandez HH, Espay AJ, Fox SH, editors. Parkinson's disease: current and future 
therapeutics and clinical trials. Cambridge: Cambridge University Press; 2016. p. 48-62.

16. Jenner P, Katzenschlager R. Apomorphine-pharmacological properties and clinical trials in Parkinson's disease. Park Relat Disord. 2016;33:S13-21.

17. Elshoff JP, Cawello W, Andreas JO, Mathy FX, Braun M. An update on pharmacological, pharmacokinetic properties and drug-drug interactions of rotigotine transdermal system in Parkinson's disease and restless legs syndrome. Drugs. 2015;75:487-501.

18. Jenner P. Wearing off, dyskinesia, and the use of continuous drug delivery in parkinson's disease. Neurol Clin. 2013;31:S17-35.

19. Kehr J, Hu X-J, Goiny M, Scheller DKA. Continuous delivery of rotigotine decreases extracellular dopamine suggesting continuous receptor stimulation. J Neural Transm. 2007;114:1027-31.

20. Hisahara S, Shimohama S. Dopamine receptors and Parkinson's disease. Int J Med Chem. 2011;2011:1-16.

21. Scheller D, Ullmer C, Berkels R, Gwarek M, Lübbert H. The in vitro receptor profile of rotigotine: a new agent for the treatment of Parkinson's disease. Naunyn Schmiedebergs Arch Pharmacol. 2009;379:73-86.

22. Chaudhuri KR. Crystallisation within transdermal rotigotine patch: Is there cause for concern? Expert Opin Drug Deliv. 2008;5:1169-71.

23. McAfee DA, Hadgraft J, Lane ME. Rotigotine: the first new chemical entity for transdermal drug delivery. Eur J Pharm Biopharm. 2014;88:586-93.

24. Blindeauer K. A controlled trial of rotigotine monotherapy in early Parkinson's disease. Arch Neurol. 2003;60:1721-8.

25. Jankovic J. Transdermal rotigotine. Arch Neurol. 2007;64:676.

26. Watts RL, Jankovic J, Waters C, Rajput A, Boroojerdi B, Rao J. Randomized, blind, controlled trial of transdermal rotigotine in early Parkinson disease. Neurology. 2007;68:272-6.

27. Giladi N, Boroojerdi B, Korczyn AD, Burn DJ, Clarke CE, Schapira AHV. Rotigotine transdermal patch in early Parkinson's disease: a randomized, double-blind, controlled study versus placebo and ropinirole. Mov Disord. 2007;22:2398-404.

28. Zhang Z-X, Shang HF, Hu X, Chen S, Zhao Z, Du X, et al. Rotigotine transdermal patch in Chinese patients with early Parkinson's disease: a randomized, double-blind, placebo-controlled pivotal study. Park Relat Disord. 2016;28:49-55.

29. Mizuno Y, Nomoto M, Kondo T, Hasegawa K, Murata M, Takeuchi M, et al. Transdermal rotigotine in early stage Parkinson's disease: a randomized, double-blind, placebo-controlled trial. Mov Disord. 2013;28:1447-50.

30. Zhang Z-X, Liu C-F, Tao E-X, Shao M, Liu Y-M, Wang J, et al. Rotigotine transdermal patch in Chinese patients with advanced Parkinson's disease: a randomized, double-blind, placebo-controlled pivotal study. Parkinsonism Relat Disord. 2017;44:6-12.

31. Nomoto M, Mizuno Y, Kondo T, Hasegawa K, Murata M, Takeuchi M, et al. Transdermal rotigotine in advanced Parkinson's disease: a randomized, double-blind, placebo-controlled trial. J Neurol. 2014;261:1887-93.

32. Nicholas AP, Borgohain R, Chaná P, Surmann E, Thompson $\mathrm{EL}$, Bauer L, et al. A randomized study of rotigotine dose response on "off" time in advanced Parkinson's disease. J Parkinsons Dis. 2014;4:361-73.

33. LeWitt PA, Lyons KE, Pahwa R. Advanced Parkinson disease treated with rotigotine transdermal system: PREFER Study. Neurology. 2007;68:1262-7.

34. Poewe WH, Rascol O, Quinn N, Tolosa E, Oertel WH, Martignoni E, et al. Efficacy of pramipexole and transdermal rotigotine in advanced Parkinson's disease: a double-blind, double-dummy, randomised controlled trial. Lancet Neurol. 2007;6:513-20.

35. Mizuno Y, Nomoto M, Hasegawa K, Hattori N, Kondo T, Murata M, et al. Rotigotine vs ropinirole in advanced stage Parkinson's disease: a double-blind study. Parkinsonism Relat Disord. 2014;20:1388-93.

36. Antonini A, Bauer L, Dohin E, Oertel WH, Rascol O, Reichmann $\mathrm{H}$, et al. Effects of rotigotine transdermal patch in patients with Parkinson's disease presenting with non-motor symptoms-results of a double-blind, randomized, placebocontrolled trial. Eur J Neurol. 2015;22:1400-7.

37. Giladi N, Nicholas AP, Asgharnejad M, Dohin E, Woltering F, Bauer L, et al. Efficacy of rotigotine at different stages of parkinson's disease symptom severity and disability: a post hoc analysis according to baseline Hoehn and Yahr stage. J Parkinsons Dis. 2016;6:741-9.

38. Frampton JE. Rotigotine transdermal patch: a review in Parkinson's disease. CNS Drugs. 2019;33:707-18.

39. Chen F, Jin L, Nie Z. Safety and efficacy of rotigotine for treating Parkinson's disease: a meta-analysis of randomised controlled trials. J Pharm Pharm Sci. 2017;20:285-94.

40. Zhuo C, Zhu X, Jiang R, Ji F, Su Z, Xue R, et al. Comparison for efficacy and tolerability among ten drugs for treatment of Parkinson's disease: a network meta-analysis. Sci Rep. 2017;8:1-14.

41. Müller T, Tolosa E, Badea L, Asgharnejad M, Grieger F, Markowitz M, et al. An observational study of rotigotine transdermal patch and other currently prescribed therapies in patients with Parkinson's disease. J Neural Transm. 2018;125:953-63.

42. Giladi N, Boroojerdi B, Surmann E. The safety and tolerability of rotigotine transdermal system over a 6-year period in patients with early-stage Parkinson's disease. J Neural Transm. 2013;120:1321-9.

43. Elmer LW, Surmann E, Boroojerdi B, Jankovic J. Long-term safety and tolerability of rotigotine transdermal system in patients with early-stage idiopathic Parkinson's disease: a prospective, open-label extension study. Parkinsonism Relat Disord. 2012;18:488-93.

44. Lewitt PA, Boroojerdi B, Surmann E, Poewe W. Rotigotine transdermal system for long-term treatment of patients with advanced Parkinson's disease: results of two open-label extension studies, CLEOPATRA-PD and PREFER. J Neural Transm. 2013;120:1069-81.

45. Trenkwalder C, Kies B, Dioszeghy P, Hill D, Surmann E, Boroojerdi B, et al. Rotigotine transdermal system for the management of motor function and sleep disturbances in Parkinson's disease: results from a 1-year, open-label extension of the RECOVER study. Basal Ganglia. 2012;2:79-85.

46. Fox SH, Katzenschlager R, Lim SY, Barton B, de Bie RMA, Seppi K, et al. International Parkinson and movement disorder society evidence-based medicine review: update on treatments for the motor symptoms of Parkinson's disease. Mov Disord. 2018;33:1248-66.

47. Chaudhuri KR, Jenner P, Antonini A. Should there be less emphasis on levodopa-induced dyskinesia in Parkinson's disease? Mov Disord. 2019;34:816-9.

48. Leta V, Jenner P, Chaudhuri KR, Antonini A. Can therapeutic strategies prevent and manage dyskinesia in Parkinson's disease? An update. Expert Opin Drug Saf. 2019;18:1203-18.

49. Giladi N, Ghys L, Surmann E, Boroojerdi B, Jankovic J. Effects of long-term treatment with rotigotine transdermal system on dyskinesia in patients with early-stage Parkinson's disease. Parkinsonism Relat Disord. 2014;20:1345-51.

50. Espay AJ, Morgante F, Merola A, Fasano A, Marsili L, Fox SH, et al. Levodopa-induced dyskinesia in Parkinson disease: current and evolving concepts. Ann Neurol. 2018;84:797-811. 
51. Sauerbier A, Chaudhuri KR. Nonmotor symptoms in Parkinson's disease. In: Jankovic J, Tolosa E, editors. Parkinson's disease \& movement disorders. 6th ed. Philadelphia: Wolters Kluwer Health; 2015. p. 137-61.

52. Storch A, Schneider CB, Wolz M, Sturwald Y, Nebe A, Odin $\mathrm{P}$, et al. Nonmotor fluctuations in Parkinson disease: severity and correlation with motor complications. Neurology. 2013;80:800-9.

53. Storch A, Schneider CB, Klingelhöfer L, Odin P, Fuchs G, Jost WH, et al. Quantitative assessment of non-motor fluctuations in Parkinson's disease using the Non-Motor Symptoms Scale (NMSS). J Neural Transm. 2015;122:1673-84.

54. Trenkwalder C, Kies B, Rudzinska M, Fine J, Nikl J, Honczarenko $\mathrm{K}$, et al. Rotigotine effects on early morning motor function and sleep in Parkinson's disease: a double-blind, randomized, placebo-controlled study (RECOVER). Mov Disord. 2011;26:90-9.

55. Rascol O, Zesiewicz T, Chaudhuri KR, Asgharnejad M, Surmann E, Dohin E, et al. A randomized controlled exploratory pilot study to evaluate the effect of rotigotine transdermal patch on Parkinson's disease-associated chronic pain. J Clin Pharmacol. 2016;56:852-61.

56. Hauser RA, Slawek J, Barone P, Dohin E, Surmann E, Asgharnejad M, et al. Evaluation of rotigotine transdermal patch for the treatment of apathy and motor symptoms in Parkinson's disease. BMC Neurol. 2016;16:1-12.

57. Chung SJ, Asgharnejad M, Bauer L, Ramirez F, Jeon B. Evaluation of rotigotine transdermal patch for the treatment of depressive symptoms in patients with Parkinson's disease. Expert Opin Pharmacother. 2016;17:1453-61.

58. Ray Chaudhuri K, Rojo JM, Schapira AHV, Brooks DJ, Stocchi F, Odin P, et al. A proposal for a comprehensive grading of Parkinson's disease severity combining motor and non-motor assessments: meeting an unmet need. PLoS ONE. 2013;8:e57221.

59. Chahine LM, Amara AW, Videnovic A. A systematic review of the literature on disorders of sleep and wakefulness in Parkinson's disease from 2005 to 2015. Sleep Med Rev. 2017;35:33-50.

60. Antonini A, Calandrella D, Merello M, Koutsikos K, Pilleri M. Effects of rotigotine on Parkinson's disease-related sleep disturbances. Expert Opin Pharmacother. 2013;14:2571-80.

61. Pierantozzi M, Placidi F, Liguori C, Albanese M, Imbriani P, Marciani MG, et al. Rotigotine may improve sleep architecture in Parkinson's disease: a double-blind, randomized, placebocontrolled polysomnographic study. Sleep Med. 2016;21:140-4.

62. Bhidayasiri R, Sringean J, Chaiwong S, Anan C, Penkeaw N, Leaknok A, et al. Rotigotine for nocturnal hypokinesia in Parkinson's disease: quantitative analysis of efficacy from a randomized, placebo-controlled trial using an axial inertial sensor. Parkinsonism Relat Disord. 2017;44:124-8.

63. Ghys L, Surmann E, Whitesides J, Boroojerdi B. Effect of rotigotine on sleep and quality of life in Parkinson's disease patients: post hoc analysis of RECOVER patients who were symptomatic at baseline. Expert Opin Pharmacother. 2011;12:1985-98.

64. Pagonabarraga J, Piñol G, Cardozo A, Sanz P, Puente V, Otermín $\mathrm{P}$, et al. Transdermal rotigotine improves sleep fragmentation in Parkinson's disease: results of the multicentre. Prospective SLEEP-FRAM Study. Parkinsons Dis. 2015;2015:1-7.

65. Ceballos-Baumann A, Häck H-J. Rotigotine transdermal patch in combination therapy for Parkinson's disease - observations in routine clinical practice. Curr Med Res Opin. 2011;27:1899-905.

66. Valldeoriola F, Salvador A, Gómez-Arguelles JM, Marey J, Moya M, Ayuga Á, et al. The effects of transdermal rotigotine on non-motor symptoms of Parkinson's disease: a multicentre, observational, retrospective, post-marketing study. Int J Neurosci. 2018;128:369-75.
67. Kim J-M, Chung SJ, Kim JW, Jeon BS, Singh P, Thierfelder S, et al. Rotigotine transdermal system as add-on to oral dopamine agonist in advanced Parkinson's disease: an open-label study. BMC Neurol. 2015;15:17.

68. Calandra-Buonaura G, Guaraldi P, Doria A, Zanigni S, Nassetti S, Favoni V, et al. Rotigotine objectively improves sleep in Parkinson's disease: an open-label pilot study with actigraphic recording. Parkinsons Dis. 2016;2016:1-5.

69. Wang Y, Yang Y-C, Lan D-M, Wu HJ, Zhao Z-X. An observational clinical and video-polysomnographic study of the effects of rotigotine in sleep disorder in Parkinson's disease. Sleep Breath. 2017;21:319-25.

70. Rosa-Grilo M, Qamar MA, Taddei RN, Pagonabarraga J, Kulisevsky J, Sauerbier A, et al. Rotigotine transdermal patch and sleep in Parkinson's disease: where are we now? NPJ Park Dis. 2017;3:28.

71. Kassubek J, Chaudhuri KR, Zesiewicz T, Surmann E, Boroojerdi B, Moran K, et al. Rotigotine transdermal system and evaluation of pain in patients with Parkinson's disease: a post hocanalysis of the RECOVER study. BMC Neurol. 2014;14:42.

72. Broen MPG, Braaksma MM, Patijn J, Weber WEJ. Prevalence of pain in Parkinson's disease: a systematic review using the modified QUADAS tool. Mov Disord. 2012;27:480-4.

73. Rukavina K, Leta V, Sportelli C, Buhidma Y, Duty S, Malcangio $\mathrm{M}$, et al. Pain in Parkinson's disease: new concepts in pathogenesis and treatment. Curr Opin Neurol. 2019;32:579-88.

74. Chaudhuri KR, Schapira AH. Non-motor symptoms of Parkinson's disease: dopaminergic pathophysiology and treatment. Lancet Neurol. 2009;8:464-74.

75. Vallderiola F, Compta Y, Aparicio J, Tarradellas J, Salazar G, Oliver JM, et al. Effects of night-time use of rotigotine on nocturnal symptoms in Parkinson's disease. Parkinsons Dis. 2015;2015:1-6.

76. Bruno AE, Sethares KA. Fatigue in Parkinson disease: an integrative review. J Neurosci Nurs. 2015;47:146-53.

77. Friedman JH, Beck JC, Chou KL, Clark G, Fagundes CP, Goetz $\mathrm{CG}$, et al. Fatigue in Parkinson's disease: report from a multidisciplinary symposium. NPJ Park Dis. 2016;2:15025.

78. Lazcano Ocampo C, Wan YM, van Wamelen DJ, Batzu L, Boura I, Titova N, et al. Identifying and responding to fatigue and apathy in Parkinson's disease: a review of current practice. Expert Rev Neurother. 2020;20:477-95.

79. Marsh L. Depression and Parkinson's disease: current knowledge. Curr Neurol Neurosci Rep. 2013;13:409.

80. Wang H, Wang L, He Y, Yu G. Rotigotine transdermal patch for the treatment of neuropsychiatric symptoms in Parkinson's disease: a meta-analysis of randomized placebo-controlled trials. J Neurol Sci. 2018;393:31-8.

81. Starkstein SE, Mayberg HS, Preziosi TJ, Andrezejewski P, Leiguarda R, Robinson RG. Reliability, validity, and clinical correlates of apathy in Parkinson's disease. J Neuropsychiatry Clin Neurosci. 1992;4:134-9.

82. Pluck GC, Brown RG. Apathy in Parkinson's disease. J Neurol Neurosurg Psychiatry. 2002;73:636-42.

83. den Brok MGHE, van Dalen JW, van Gool WA, Moll van Charante EP, de Bie RMA, Richard E. Apathy in Parkinson's disease: a systematic review and meta-analysis. Mov Disord. 2015;30:759-69.

84. Magerkurth C, Schnitzer R, Braune S. Symptoms of autonomic failure in Parkinson's disease: prevalence and impact on daily life. Clin Auton Res. 2005;15:76-82.

85. Batla A, Phé V, De Min L, Panicker JN. Nocturia in Parkinson's disease: why does it occur and how to manage? Mov Disord Clin Pract. 2016;3:443-51.

86. Giladi N, Fichtner A, Poewe W, Boroojerdi B. Rotigotine transdermal system for control of early morning motor impairment 
and sleep disturbances in patients with Parkinson's disease. J Neural Transm. 2010;117:1395-9.

87. Woitalla D, Kassubek J, Timmermann L, Lauterbach T, Berkels $\mathrm{R}$, Grieger F, et al. Reduction of gastrointestinal symptoms in Parkinson's disease afteraswitch from oral therapy to rotigotine transdermal patch: anon-interventional prospective multicenter trial. Park Relat Disord. 2015;21:199-204.

88. Alty J, Robson J, Duggan-Carter P, Jamieson S. What to do when people with Parkinson's disease cannot take their usual oral medications. Pract Neurol. 2016;16:122-8.

89. Lahner E, Virili C, Santaguida MG, Annibale B, Centanni M. Helicobacter pylori infection and drugs malabsorption. World $\mathbf{J}$ Gastroenterol. 2014;20:10331-7.

90. Lee WY, Yoon WT, Shin HY, Jeon SH, Rhee P-L. Helicobacter pylori infection and motor fluctuations in patients with Parkinson's disease. Mov Disord. 2008;23:1696-700.

91. Miller N, Allcock L, Hildreth AJ, Jones D, Noble E, Burn DJ. Swallowing problems in Parkinson disease: frequency and clinical correlates. J Neurol Neurosurg Psychiatry. 2009;80:1047-9.

92. Kalf JG, de Swart BJM, Bloem BR, Munneke M. Prevalence of oropharyngeal dysphagia in Parkinson's disease: a meta-analysis. Parkinsonism Relat Disord. 2012;18:311-5.

93. Miller N, Noble E, Jones D, Burn D. Hard to swallow: dysphagia in Parkinson's disease. Age Ageing. 2006;35:614-8.

94. Plowman-Prine EK, Sapienza CM, Okun MS, Pollock SL, Jacobson $\mathrm{C}, \mathrm{Wu} \mathrm{SS}$, et al. The relationship between quality of life and swallowing in Parkinson's disease. Mov Disord. 2009;24:1352-8.

95. Morgante L, Salemi G, Meneghini F, Di Rosa AE, Epifanio A, Grigoletto F, et al. Parkinson disease survival. Arch Neurol. 2000;57:507.

96. Suttrup I, Warnecke T. Dysphagia in Parkinson's disease. Dysphagia. 2016;31:24-32.

97. Hirano M, Isono C, Sakamoto H, Ueno S, Kusunoki S, Nakamura Y. Rotigotine transdermal patch improves swallowing in dysphagic patients with Parkinson's disease. Dysphagia. 2015;30:452-6.

98. Nicaretta DH, Rosso AL, de Mattos JP, Maliska C, Costa MMB. Dysphagia and sialorrhea: the relationship to Parkinson's disease. Arq Gastroenterol. 2013;50:42-9.

99. Ou R, Guo X, Wei Q, Cao B, Yang J, Song W, et al. Prevalence and clinical correlates of drooling in Parkinson disease: a study on 518 Chinese patients. Parkinsonism Relat Disord. 2015;21:211-5.

100. Srivanitchapoom P, Pandey S, Hallett M. Drooling in Parkinson's disease: a review. Park Relat Disord. 2014;20:1109-18.

101. van Wamelen DJ, Leta V, Johnson J, Ocampo CL, Podlewska AM, Rukavina K, et al. Drooling in Parkinson's disease: prevalence and progression from the non-motor international longitudinal study. Dysphagia. 2020;35:955-61.

102. Schirinzi T, Imbriani P, D’Elia A, Di Lazzaro G, Mercuri NB, Pisani A. Rotigotine may control drooling in patients with Parkinson's disease: preliminary findings. Clin Neurol Neurosurg. 2017;156:63-5.

103. Adler CH. Relevance of motor complications in Parkinson's disease. Neurology. 2002;58:S51-6.

104. Stocchi F. Prevention and treatment of motor fluctuations. Parkinsonism Relat Disord. 2003;9:73-81.

105. Isaacson SH, Chaudhuri KR. Morning akinesia and the potential role of gastroparesis - managing delayed onset of first daily dose of oral levodopa in patients with Parkinson's disease. Eur Neurol Rev. 2013;8:82.

106. Rizos A, Martinez-Martin P, Odin P, Antonini A, Kessel B, Kozul TK, et al. Characterizing motor and non-motor aspects of early-morning off periods in Parkinson's disease: an international multicenter study. Park Relat Disord. 2014;20:1231-5.
107. Cochen De Cock V. Therapies for restless legs in Parkinson's disease. Curr Treat Options Neurol. 2019;21:56.

108. Winkelmann J, Allen RP, Högl B, Inoue Y, Oertel W, Salminen AV, et al. Treatment of restless legs syndrome: evidence-based review and implications for clinical practice (revised 2017). Mov Disord. 2018;33:1077-91.

109. Covassin N, Neikrug AB, Liu L, Corey-Bloom J, Loredo JS, Palmer BW, et al. Clinical correlates of periodic limb movements in sleep in Parkinson's disease. J Neurol Sci. 2012;316:131-6.

110. Happe S, Trenkwalder C. Movement disorders in sleep: Parkinson's disease and restless legs syndrome. Motorische Störungen im Schlaf: M. Parkinson und restless legs syndrome. Biomed Tech Eng. 2003;48:62-7.

111. Reichmann H. Perioperatives Management von ParkinsonPatienten. Fortschritte der Neurol Psychiatr. 2016;84:S14-7.

112. Simonet C, Tolosa E, Camara A, Valldeoriola F. Emergencies and critical issues in Parkinson's disease. Pract Neurol. 2020;20:15-25.

113. Wüllner U, Kassubek J, Odin P, Schwarz M, Naumann M, Häck $\mathrm{H}-\mathrm{J}$, et al. Transdermal rotigotine for the perioperative management of Parkinson's disease. J Neural Transm. 2010;117:855-9.

114. Chung SJ, Kim JM, Kim JW, Jeon BS, Singh P, Thierfelder S, et al. Switch from oral pramipexole or ropinirole to rotigotine transdermal system in advanced Parkinson's disease: an openlabel study. Expert Opin Pharmacother. 2015;16:961-70.

115. Güldenpfennig WM, Poole KH, Sommerville KW, Boroojerdi B. Safety, tolerability, and efficacy of continuous transdermal dopaminergic stimulation with rotigotine patch in earlystage idiopathic Parkinson disease. Clin Neuropharmacol. 2005;28:106-10.

116. Woitalla D, Dunac A, Safavi A, Ceravolo MG, Gomez Esteban JC, Pavese N, et al. A noninterventional study evaluating the effectiveness of rotigotine and levodopa combination therapy in younger versus older patients with Parkinson's disease. Expert Opin Pharmacother. 2018;19:937-45.

117. Brennan KA, Genever RW. Practice pointer: managing Parkinson's disease during surgery. BMJ. 2010;341:990-3.

118. Magdalinou KN, Martin A, Kessel B. Prescribing medications in Parkinson's disease (PD) patients during acute admissions to a District General Hospital. Park Relat Disord. 2007;13:539-40.

119. Onofrj M, Thomas A. Acute akinesia in Parkinson disease. Neurology. 2005;64:1162-9.

120. Newman EJ, Grosset DG, Kennedy PGE. The parkinsonismhyperpyrexia syndrome. Neurocrit Care. 2009;10:136-40.

121. Loddo G, Calandra-Buonaura G, Sambati L, Giannini G, Cecere A, Cortelli P, et al. The treatment of sleep disorders in Parkinson's disease: from research to clinical practice. Front Neurol. 2017;8:42.

122. Todorova A, Martinez-Martin P, Martin A, Rizos A, Reddy P, Chaudhuri KR. Daytime apomorphine infusion combined with transdermal Rotigotine patch therapy is tolerated at 2 years: A 24-h treatment option in Parkinson's disease. Basal Ganglia. 2013;3:127-30.

123. Leta V, van Wamelen DJ, Sauerbier A, Jones S, Parry M, Rizos A, et al. Opicapone and levodopa-carbidopa intestinal gel infusion: the way forward towards cost savings for the healthcare systems? J Parkinsons Dis. 2020;10:1535-9.

124. Fitzsimmons PR, Blayney S, Mina-Corkill S, Scott GO. Older participants are frequently excluded from Parkinson's disease research. Park Relat Disord. 2012;18:585-9.

125. Fasano A, Guidubaldi A, Nigris F, Bentivoglio AR. Safety and efficacy of rotigotine in individuals with Parkinson's disease aged 75 and older. J Am Geriatr Soc. 2011;59:2386-7.

126. Shulman LM, Minagar A, Rabinstein A, Weiner WJ. The use of dopamine agonists in very elderly patients with Parkinson's disease. Mov Disord. 2000;15:664-8. 
127. Oertel W, LeWitt P, Giladi N, Ghys L, Grieger F, Boroojerdi B. Treatment of patients with early and advanced Parkinson's disease with rotigotine transdermal system: age-relationship to safety and tolerability. Park Relat Disord Elsevier Ltd. 2013;19:37-42.

128. Nomoto M, Iwaki H, Kondo H, Sakurai M. Efficacy and safety of rotigotine in elderly patients with Parkinson's disease in comparison with the non-elderly: a post hoc analysis of randomized, double-blind, placebo-controlled trials. J Neurol. 2018;265:253-65.

129. Rizos A, Sauerbier A, Falup-Pecurariu C, Odin P, Antonini A, Martinez-Martin P, et al. Tolerability of non-ergot oral and transdermal dopamine agonists in younger and older Parkinson's disease patients: an European multicentre survey. J Neural Transm. 2020;127:875-9.

130. Latt MD, Lewis S, Zekry O, Fung VSC. Factors to consider in the selection of dopamine agonists for older persons with Parkinson's disease. Drugs Aging. 2019;36:189-202.

131. Sieb JP, Themann P, Warnecke T, Lauterbach T, Berkels R, Grieger F, et al. Caregivers' and physicians' attitudes to rotigotine transdermal patch versus oral Parkinson's disease medication: an observational study. Curr Med Res Opin. 2015;31:967-74.

132. Antonini A, Chaudhuri KR, Boroojerdi B, Asgharnejad M, Bauer $\mathrm{L}$, Grieger $\mathrm{F}$, et al. Impulse control disorder related behaviours during long-term rotigotine treatment: a post hoc analysis. Eur J Neurol. 2016;23:1556-65.

133. Weintraub D, Koester J, Potenza MN, Siderowf AD, Stacy M, Voon V, et al. Impulse control disorders in Parkinson disease. Arch Neurol. 2010;67:589-95.

134. Rizos A, Sauerbier A, Antonini A, Weintraub D, MartinezMartin P, Kessel B, et al. A European multicentre survey of impulse control behaviours in Parkinson's disease patients treated with short- and long-acting dopamine agonists. Eur J Neurol. 2016;23:1255-61.

135. Garcia-Ruiz PJ, Martinez Castrillo JC, Alonso-Canovas A, Herranz Barcenas A, Vela L, Sanchez Alonso P, et al. Impulse control disorder in patients with Parkinson's disease under dopamine agonist therapy: a multicentre study. J Neurol Neurosurg Psychiatry. 2014;85:840-4.
136. Samuel M, Rodriguez-Oroz M, Antonini A, Brotchie JM, Ray Chaudhuri K, Brown RG, et al. Management of impulse control disorders in Parkinson's disease: controversies and future approaches. Mov Disord. 2015;30:150-9.

137. Chaudhuri KR, Todorova A, Nirenberg MJ, Parry M, Martin A, Martinez-Martin P, et al. A pilot prospective, multicenter observational study of dopamine agonist withdrawal syndrome in Parkinson's disease. Mov Disord Clin Pract. 2015;2:170-4.

138. Timmermann L, Oehlwein C, Ransmayr G, Fröhlich H, Will E, Schroeder H, et al. Patients' perception of Parkinson's diseaseassociated pain following initiation of rotigotine: a multicenter non-interventional study. Postgrad Med Taylor \& Francis. 2017;129:46-54.

139. Sanford M, Scott LJ. Rotigotine transdermal patch: a review of its use in the treatment of parkinsons disease. CNS Drugs. 2011;25:699-719.

140. Isooka N, Miyazaki I, Kikuoka R, Wada K, Nakayama E, Shin $\mathrm{K}$, et al. Dopaminergic neuroprotective effects of rotigotine via 5-HT1A receptors: possibly involvement of metallothionein expression in astrocytes. Neurochem Int. 2020;132:104608.

141. Timmermann L, Asgharnejad M, Boroojerdi B, Dohin E, Woltering F, Elmer LW. Impact of 6-month earlier versus postponed initiation of rotigotine on long-term outcome: post hoc analysis of patients with early Parkinson's disease with mild symptom severity. Expert Opin Pharmacother. 2015;16:1423-33.

142. Wang F, Yang Z, Liu M, Tao Y, Li Z, Wu Z, et al. Facile noseto-brain delivery of rotigotine-loaded polymer micelles thermosensitive hydrogels: in vitro characterization and in vivo behavior study. Int J Pharm. 2020;577:119046.

143. Bhattamisra SK, Shak AT, Xi LW, Safian NH, Choudhury H, Lim WM, et al. Nose to brain delivery of rotigotine loaded chitosan nanoparticles in human SH-SY5Y neuroblastoma cells and animal model of Parkinson's disease. Int J Pharm. 2020;579:119148.

144. Olanow CW, Standaert DG, Kieburtz K, Viegas T, Moreadith R. Once-weekly subcutaneous delivery of polymer-linked rotigotine (SER-214) provides continuous plasma levels in Parkinson's disease patients. Mov Disord. 2020;35:1055-61. 